\title{
RECENSIÓN
}

\section{LA EVALUACIÓN DE PROGRAMAS DE OCIO ALTERNATIVO DE FIN DE SEMANA}

\author{
Domingo Comas \\ ISBN: 84-89582-74-2 \\ Edita: Instituto de la Juventud \\ 111 páginas
}

Recensión por: Teresa Robledo de Dios. Jefa del Servicio de Promoción de Hábitos Saludables. Dirección General de Salud Pública y Consumo. Ministerio de Sanidad y Consumo

Los programas de ocio alternativo para jóvenes, en horario nocturno de fin de semana, han pasado a conformarse, en apenas tres años, en un fenómeno masivo, del que disponemos información muy fragmentada.

Este libro, recientemente editado por el Instituto de la Juventud, y escrito por el profesor Domingo Comas, nos permite una clara aproximación a lo que son, hoy día, los programas de ocio alternativo de fin de semana en España, a la vez que presenta una reflexión en torno a la evaluabilidad de los mismos.

El libro se estructura en siete capítulos y un apartado bibliográfico.

En el primer capítulo se presentan los objetivos de esta publicación y la metodología utilizada para alcanzarlos. Como ya se ha señalado, no se trata de una evaluación de los programas de ocio alternativo vigentes en España, sino de presentar un manual de evaluación para este tipo de programas.

Para el análisis de situación se han utilizado técnicas sistemáticas de recogida de datos (cuestionarios...), y se ha analizado la información obtenida de diferentes Seminarios, realizados al efecto (Encuentros de Cabueñes), y la procedente de diferentes Jornadas y Seminarios realizados dentro del Foro INJUVE.
El segundo capítulo realiza un análisis muy exhaustivo de los programas de ocio alternativo nocturno de fin de semana.

Se analiza el contexto social, institucional y científico que determina la aparición y consolidación de estos programas, a la vez que se resalta el protagonismo de los ámbitos de Juventud en el desarrollo e implantación de dichos programas en España. También analiza las implicaciones económicas y sociales del nuevo fenómeno del fin de semana, así como las diferencias territoriales del mismo.

Finalmente presenta un perfil global de los programas de ocio alternativo, analizando los diferentes enfoques (el de la prevención de riesgos y el de la promoción de un ocio lúdico).

En el resto de capítulos se presenta la forma en que podemos evaluar estos contenidos. Partiendo de una propuesta para evaluar los programas de ocio alternativo de fin de semana, que se han generalizado en España en los últimos años, se propone una visión ética de la evaluación, en la que se combinan metodologías cualitativas y cuantitativas, para desarrollar un modelo comprensivo y equitativo de evaluación.

El capítulo tercero, sobre una propuesta general de evaluación, analiza el perfil profesional de los evaluadores y propone un 
modelo de evaluación particular, adaptado y exclusivo para este tipo de programas.

El primer paso de esta evaluación referido al análisis de la realidad, la evaluación de las necesidades y el diseño del programa se presenta en el capítulo cuarto.

El quinto se refiere al segundo paso, el de la evaluación del proceso, que es la parte de la evaluación más estandarizada, dirigida a establecer la calidad del trabajo al margen de su significado social.

Finalmente, se presenta en el capítulo sexto la evaluación del impacto. La técnica propuesta para ello son los Grupos de Discusión.

El último capítulo titulado «El lugar de la evaluación en los programas de ocio alternativo de fin de semana», presenta una visión sintética de todo el contenido recogido en la publicación, a la vez que abre algunas cuestiones que pueden quedar pendientes.

En definitiva, este libro proporciona una concienzuda aproximación a lo que son los programas de ocio alternativo nocturno de fin de semana y a la forma en que podemos evaluarlos. Siendo de gran utilidad para todos aquellos profesionales que trabajan en estos y otros programas equivalentes. 